\title{
ATIVIDADE E CRIAÇÃO: A POLÍTICA DE ASSISTÊNCIA SOCIAL EM PERMANENTE(RE)CONSTRUÇÃO PELA ANÁLISE MICROPOLIITICA DO TRABALHO
}

\author{
ACTIVITY AND CREATION: THE SOCIAL ASSISTANCE POLICY IN PERMANENT (RE) \\ CONSTRUCTION BY MICROANALYSIS OF THE WORK.
}

ACTIVIDAD Y CREACIÓN: LA POLÍTICA DE ASISTENCIA SOCIAL EN PERMANENTE (RE) CONSTRUCCIÓN POR LA MICROANÁLISIS DEL TRABAJO.

Gabriela Girardi Hall

Fernanda Spanier Amador

\begin{abstract}
RESUMO
As experiências junto ao campo da Assistência Social de Porto Alegre, durante o percurso de graduação em Psicologia, produziram inquietações, principalmente no que diz respeito aos modos de trabalhar nesse contexto. A fim de contribuir com o debate atual acerca das políticas públicas no país, neste escrito se propõe uma conversa com conceitos propostos pela Esquizoanálise e pela Ergologia, especialmente o de micropolítica e o de atividade, visando traçar um plano problemático referente à Política Nacional de Assistência Social. Com o olhar para a micropolítica do trabalho, investimos em uma análise da gestão do/no trabalho e apostamos na atividade dos trabalhadores como estratégia de criação e recriação constante de práticas coletivas que resistam à captura por modelos instituídos nos processos de trabalho.
\end{abstract}

Palavras-chave: Atividade. Micropolítica. Assistência Social.

\section{ABSTRACT}

The experiences on the field of Social Assistance in Porto Alegre during the graduation in psychology, produced disquiets, mainly, with regard to the ways of working in that context. In order to contribute to the current debate about public policy in the country, is proposed in this written a dialogue between concepts proposed by Schizoanalysis and the Ergology, especially micropolitics and activity, aiming to trace a problematic plan of the Nacional Social Assistance Policy. With the focus on the micropolitics of the work, we invest in a management analysis of/at work and endue the activity of employees as a constant creation and reinvention strategy of

\footnotetext{
* Graduada em Psicologia pela Universidade Federal do Rio Grande do Sul e integrante da Rede Multicêntrica - Centro de Referência em Educação Permanente e Apoio Institucional para Políticas de Cuidado ao Uso de Drogas. E-mail: gabrielaghall@ gmail.com

** Psicóloga e docente do Instituto de Psicologia/UfRGS, com atuação no Departamento de Psicologia Social e Institucional e no Programa de Pós-Graduação em Psicologia Social e Institucional/UFRGS. E-mail: feamador@uol.com.br
} 
collective practices that resist to the capture by established models in work processes.

Keywords: Activity. Micropolitics. Social Assistance.

\section{RESUMEN}

Los experimentos con el campo de la Asistencia Social de Porto Alegre, en el curso de graduación en psicología, produjeron inquietudes, sobre todo con respecto a las formas de trabajar en este contexto. Con el fin de contribuir al debate actual sobre la política pública en el país, este escrito propone una conversación con los conceptos propuestos por la Esquizoanálisis y la Ergología, especialmente la micropolítica y la actividad, dirigida a trazar un plan problemático relacionado con la Política Nacional del Asistencia Social. Con la mirada en las micropolíticas del trabajo, invertimos en una análisis de la gestión en el/del trabajo y apostamos en la actividad de los trabajadores como una estrategia de creación de y recreación constante de prácticas colectivas que resisten a ser capturadas por los modelos instituidos en los procesos de trabajo.

Palabras clave: Actividad. Micropolíticas. Asistencia Social.

\section{INTRODUÇÃO}

recente implementação do Sistema Único de Assistência Social (SUAS)
tem convocado à discussão tanto os trabalhadores antes envolvidos com
as questōes do campo assistencial quanto instituições de formação dos profissionais, além de todos aqueles que se consideram responsáveis, atingidos e/ ou interessados pelos modos de organização, de gestão e de atenção das políticas públicas do Brasil. A aprovação, em 2004, da Política Nacional de Assistência Social (PNAS) e a regulação, em 2010, do SUAS reafirmam o que já indicava a Lei Orgânica de Assistência Social (LOAS, 1993): a ruptura com uma concepção assistencialista, benemerente e voluntarista, reconhecendo e legitimando, assim, as demandas de seus usuários como especificidade no campo das políticas públicas, "exigindo que as provisões assistenciais sejam prioritariamente pensadas em âmbito das garantias de cidadania sob vigilância do Estado" (Cruz \& Guareschi, 2009, p. 28).

Tratando-se de uma área histórica e culturalmente atribuída à generosidade dos cuidados de entidades privadas, à filantropia e à caridade, faz-se necessário, portanto, o constante debate a respeito dos modos como a Política se faz no cotidiano de trabalho dos serviços, visando à discussão de dimensões relativas à organização, aos princípios e às diretrizes da PNAS, mas, sobretudo, fazendo-o 
no lastro de uma análise das dimensões ético-político-estéticas do trabalho na assistência. Ou seja, considerando as experiências de autogestão que permitem desconstruir a verdade das regras preconcebidas e abrindo outras possibilidades de criação e recriação para novos modos de existir coletivamente, conforme apresentam Rocha, Montano e Pimenta (2012).

Temos acompanhado, na consolidação do Sistema Único de Saúde (SUS), uma preocupação com a reorganização dos serviços e o reposicionamento dos trabalhadores da saúde a partir da lógica da humanização, na tentativa de problematizar a prevalência do discurso médico sobre a doença, apostando na integralidade dos atendimentos, bem como de investir no protagonismo do usuário, desnaturalizando a posição de um "não saber" sobre si mesmo e sobre o seu corpo, cultivada, muitas vezes, pela postura dos especialistas. No campo da assistência, também urge ampliar a discussão sobre a prevalência dos discursos assistencialistas sobre a pobreza. Discursos esses que, embora repensados pela PNAS, ainda prevalecem e, disfarçados pelo mesmo título de "especialistas", intensificam e fazem perpetuar a lógica da exclusão social.

Ao trabalhador da assistência, portanto, cabe não só o trabalho, muitas vezes, doloroso ao lidar com as situações de extrema exclusão social e de miséria, de violência e de riscos, mas também o de responder a certa demanda de "adaptação" às mudanças de concepções e de posições que são preconizadas na PNAS ${ }^{1}$. Assim, analisar o trabalho na assistência social nos põe a repensar o modo como se instituiu e a forma como o mesmo está organizado. Porém, além da esfera macropolítica, acreditamos que as estratégias de análise devem atentar à micropolítica dos modos de trabalhar e, principalmente, incorporá-la. O real do trabalho, as situações inusitadas do cotidiano, convocam o trabalhador em assistência a criar modos de intervir que transpõem a ordem do instituído. Conforme Mehry (2009), não bastará corrigir os procedimentos organizacionais e financeiros das instituições, se o modo como os trabalhadores se relacionam com seu objeto de trabalho não for constantemente repensado.

Pensando no contexto da saúde, o qual podemos aproximar do momento em que se constitui a assistência, Benevides (como citado em Barros \& Pimentel, 2012, p. 2) afirma que "construir políticas públicas na máquina do Estado exige todo um trabalho de conexão com as forças do coletivo, com os movimentos sociais, com as práticas concretas no cotidiano dos serviços de saúde". Se utilizarmos o ponto de vista da autora, podemos pensar que a coletivização do trabalho e no trabalho nos aponta pistas para repensar o trabalho na assistência. Tornase, assim, interessante a busca por espaços nos quais os trabalhadores possam

1 É importante considerar os convênios público-privados que mantêm a execução da PNAS, sendo que a maioria das instituiçōes envolvidas, religiosas, já trabalhavam com a filantropia antes da instituição da política. Além disso, consideramos a própria subjetivação dos trabalhadores, mesmo daqueles que ingressam via concurso público, em uma cultura assistencialista no Brasil. 
compartilhar experiências, coletivos de discussão que suscitem a emergência de problemáticas comuns do fazer cotidiano, um compartilhar das dificuldades produzidas nas incertezas e inconstâncias do e no trabalho, encontros nos quais se possam transformar as queixas em intervenções potenciais.

Este escrito se desencadeia, portanto, a partir do encontro possibilitado pela função de estagiária durante o curso de Psicologia da Universidade Federal do Rio Grande do Sul (UFRGS), junto a um serviço da rede de Assistência de Porto Alegre em 2012. Prolongou-se como Trabalho de Conclusão de Curso, devido às inquietações provocadas pelas experiências em campo. Tais inquietações demandaram outros olhares e levaram à análise singular dos afetos sucedidos nesses encontros - por afeto entendemos a "força desconhecida a partir da qual temos que aprender algo no presente, sem salva-vidas, nem garantias" (Lazzarotto \& Carvalho, 2012, p. 26).

Neste artigo propomos retomar a concepção de Assistência Social enquanto Política de Seguridade Social e sua constituição enquanto Sistema Único, pensando na herança deixada pela "cultura tutelar" no trabalho que se realiza pelos serviços e equipes da Assistência Social, visando operar em sua transformação. Fazemos uso dos referenciais teóricos da Esquizoanálise e da Ergologia, contando com autores contemporâneos que discutem esses conceitos no campo da saúde para a análise dos processos de trabalho, entendendo o trabalho como espaço e como ato de criação, não somente de submissão e disciplina. A política, portanto, não se constitui meramente pelo que determinam os documentos oficiais, mas se faz e refaz por entre a atividade do trabalhador da assistência.

\section{DE INDIVÍDUOS “CARENTES” A SUJEITOS DE DIREITOS: DESNATURALIZANDO O ASSISTENCIALISMO}

Longe, portanto, de assumir o formato de política social, a assistência social desenrolou-se ao longo de décadas, como doaçôes de auxílios, revestida pela forma de tutela, de benesse, de favor, sem superar o caráter de prática circunstancial, secundária e imediatista que, no fim, mais reproduz a pobreza e a desigualdade social na sociedade brasileira, já que opera de forma descontínua em situações pontuais (Mestriner, 2008, p. 16).

Couto (2009) afirma que a materialização do SUAS é uma tarefa desafiadora, pensando em uma política pública nacional articulada, tratando-se de uma área histórica e culturalmente atribuída à generosidade dos cuidados de entidades privadas, à filantropia e à caridade. Tanto as publicações recentes sobre o tema quanto a prática do trabalho na assistência, a qual será retomada e relatada no decorrer deste escrito, nos conduzem à tentativa de compreender, ou ainda, 
problematizar sobre a complexidade que é fazer política pública em um campo permeado por discursos conservadores e institucionalizados, visando trabalhar na garantia de direitos e não mais se resumir às práticas de subalternização. Aguinsky, Fernandes e Tejadas (2009) apontam para o movimento de resistência, que os atores envolvidos na Política precisam exercer, cotidianamente, e para os processos moralizantes e opressivos que se apresentam de modo insistente nas tramas constitutivas da materialização do direito à Assistência Social. Para tanto, faz-se necessário também a discussão de quem são os destinatários da Política, retomando alguns aspectos da história das açôes assistenciais.

A compreensão desses determinantes históricos, conforme as autoras, é essencial para projetar o presente e o futuro da Política de Assistência Social, "uma vez que o novo não supera o velho de um dia para o outro, ou melhor, novo e velho [Assistência Social e Assistencialismo] misturam-se na prática cotidiana dos trabalhadores, dos gestores e dos usuários" (Aguinsky, Fernandes, \& Tejadas, 2009, p. 65). Problematizar o conservadorismo nos modos que configuram as ações nessa área, a tradição clientelista e assistencialista, nos direciona para o campo dos direitos humanos, entendendo que os usuários, além de economicamente instáveis e vulneráveis, estão fragilizados jurídica e politicamente enquanto cidadãos de direitos, ou seja, seus direitos fundamentais de sobrevivência não estão sendo promovidos, protegidos, nem garantidos (Aguinsky et al., 2009). Nesse sentido, tal concepção de assistência imbricado com os modos tutelares não favorece um protagonismo e emancipação dos usuários desses serviços, ao contrário, "os cidadãos continuam a se portar frente ao Estado como solicitantes, e não como parte de um coletivo atuante" (Mestriner, 2008, p. 29).

Aguinsky et al. (2009) apontam que, além da dimensão material, não podemos ignorar que são múltiplos os fenômenos inter-relacionados na produção de vulnerabilidade, cujas determinaçôes se relacionam dialeticamente à ordem econômica. Na sequência, as autoras indicam a noção de risco social que se constitui justamente nesse convívio social fragilizado, nas relaçôes humanas, que expressam uma condição de vida dessas populaçóes quando remetidas às condiçôes de pobreza e de desigualdade social. A pobreza, sendo fenômeno que emerge do capitalismo, da organização social a partir da exploração do trabalho, ou seja, a pobreza, enquanto produção social, determina escolhas, condições e modos de vida, e demarca um lugar social a ser habitado, lugar inferior e desvalorizado, que condiciona experiências e relações sociais. Assim, os padrões de vida e bem-estar socialmente aceitos, em uma determinada cultura e em certo momento histórico, são condição que determina a diferença e a classificação social dos que a têm e dos que não a têm. E os que não a têm são vistos como sinônimo de fracasso social e de desqualificação moral. Conforme Aguinsky et al. (2009) destaca na leitura de Yasbek: 
São produtos dessas relações [a pobreza, a exclusão e a subalternidade], que produzem e reproduzem a desigualdade no plano social, político, econômico e cultural, definindo para os pobres um lugar na sociedade. Um lugar onde são desqualificados nas suas crenças, seu modo de expressar-se e seu comportamento social, sinais de 'qualidades negativas' e indesejáveis que lhe são conferidas por procedência de classe, por sua condição social (Yasbek apud Aguinsky et al., 2009, p. 72).

Desse modo, pode-se pensar a condição de pobreza social como própria violação de direitos, sendo que essa situação exclui esses sujeitos dos debates políticos sobre as suas próprias condições de vida. Aqui apontamos para a tentativa custosa de implementar uma política que tem como base o eixo da participação dos usuários, usuários emudecidos pelo processo de exclusão e opressão, opressão que se reproduz facilmente nos serviços que atualmente realizam as ações da assistência, caindo em uma relação moralizante e controladora.

Entre o pesado legado de tradição autoritária e excludente e as mudanças em curso no mundo contemporâneo, o cenário público brasileiro está atravessado por alternativas antagônicas de futuro, contrapondo, de um lado, as possibilidades de uma regulação democrática da vida social que tenha como medida o reconhecimento e a generalização de direitos e, de outro, propostas neoliberais que representam uma tentativa de privatização das relações sociais pela recusa da mediação pública dos direitos e esferas de representação (Paoli \& Telles apud Couto \& Silva, 2009, p. 42).

Assim, a assistência social se propõe a enfrentar e criar intervenções direcionadas a esse território de disputa entre o privado e o público, que tem como características a pobreza, a vulnerabilidade e os riscos sociais. Território entre a exclusão e a proteção, entre a violação e o direito.

\section{CONSTRUÇÃO DO PÚBLICO: O COMUM NA ATIVIDADE DO TRABALHO NA ASSISTÊNCIA}

Para pensar o campo das políticas públicas, Barros e Pimentel (2012) discutem os próprios termos que compõem esse "ente" que é uma política pública, demonstrando a complexidade de fazer com que a política seja, de fato, pública.

Retomando filósofos, as autoras consideram política, então, “a atividade humana que, ligada ao poder, coloca em relação sujeitos, articulando-os segundo regras ou normas não necessariamente jurídicas ou legais" (Barros \& Pimentel, 2012, p. 8). Essa definição faz deslocar o termo de um centro de poder, representado pelo Estado ou por certa classe, e considera também seu "exercício em arranjos locais, por microrrelações, indicando a direção micropolítica das relaçôes de poder" (p. 8). Assim, consideramos que a política pode ser exercida 
por cada um de nós, em toda atividade humana, nas nossas relaçóes cotidianas, nas diversas esferas que compõem a vida. Considerando que o político não necessariamente diz de um poder ou regras referentes ao Estado, qual seria o caráter público nas ações do Estado, visto que uma ação estatal não garante uma prática pública?

Como abordamos anteriormente, as bordas entre o público e o privado nas ações das políticas públicas, dando ênfase à assistência social, que permaneceu por décadas associada às iniciativas privadas, e a sobreposição de discursos liberais na contramão de propostas que sustentam a posição da Constituição na garantia dos direitos fundamentais como função do Estado, compõem um território conflituoso no contexto brasileiro. Para as autoras, uma pista para a produção das políticas públicas é considerar a dimensão do comum. O comum constitui-se na multiplicidade do diferente, das diferenças singulares desses muitos que compóem, que participam, que executam, que planejam, que não somente demandam por uma política, por ações e por direitos, mas cogerenciam essas ações de forma transversal, como uma rede multivetorializada:

Comum não é uma identidade, não se confunde com povo, nem é uniformidade como as massas; são as diferenças internas que devem fazer comunicar as diferenças e agir em conjunto. Aqui um paradoxo: uma multiplicidade social se comunica e age em comum ao mesmo tempo em que reverbera diferenças. Esse comum se faz como rede heterogênea, dispersa, complexa e multidirecional (Barros \& Pimentel, 2012, p. 10).

Assim, trabalhar com/nessa dimensão do comum é trabalhar com/nessa abertura ao outro, compondo com as singularidade e acolhendo a multiplicidade $\mathrm{r}$ a heterogeneidade. É o alargamento das capacidaded de comunicar e compartilhar, proliferando redes. Segundo Barros e Pimentel (2012), o comum se refere a um estado de abertura à multiplicidade de encontros e aos modos de viver junto, na diferença, o que impossibilita, ou, ao menos, dificulta a captura por formas preestabelecidas.

Considerando, portanto, a dimensão do "comum" pelo fazer das políticas públicas, é de se pensar nesse conceito na esfera das relaçôes entre trabalhadores e, também, entre esses e os usuários das políticas, ou seja, entre todos os atores que compõem o cenário dessa arte que tem no seu enredo os processos de trabalho e a (re)construção compartilhada de políticas públicas.

No trabalho da assistência, esse exercício de produção do comum corresponderia a modos de operar no cotidiano por espaços de partilha, de troca e de produção de diferença. Assim, o comum, nesse trabalho, advém da experiência, somente em ato, nos meandros dos acontecimentos do cotidiano laboral, e da mobilização e implicação dos trabalhadores em produzir sentido 
no seu trabalho. Se entendemos que uma política pública se faz pelo exercício constante de produção desse comum, e que esse exercício se dá pela experiência e pela afetação nas relações de trabalho, e não somente pela imposição vertical de leis e de normativas, faz-se necessário adentrarmos na discussão sobre a atividade do trabalhador enquanto espaço-tempo de criação e recriação da própria política.

A atividade, segundo Schwartz (2011), é a convidada da qual não podemos nos esquivar na discussão e na análise do trabalho, como as pessoas se relacionam a partir dele e com ele, já que não podemos descartar a singularidade de qualquer ação humana. Conforme o autor, a racionalidade de normas que antecipam o nosso agir não dissipa a obrigação que cada um tem de repensar, intimamente, suas escolhas de ser e de se situar de uma maneira ou de outra no mundo. Na distância entre o trabalho prescrito e o trabalho real, a atividade, enquanto processo de produção singular de certos conhecimentos do trabalhador no encontro com o campo de ação, convoca-nos ao debate das normas e dos modelos, a fim de apreciar e considerar "a vida que surge a todo instante" (Schwartz, 2011, p. 137).

O autor propõe que nos afastemos dessa forma instituída de avaliar e de tomar decisóes sobre o "desempenho" do trabalhador e do trabalho apenas pelos resultados finais. Avaliar de modo puramente quantitativo a atividade humana seria uma forma de ocultar as múltiplas dramáticas humanas, suprir as singularidades de cada processo de trabalho, da relação do trabalhador com seu trabalho, podendo gerar custos e crises mais amplas em uma escala social. Nessa via de analisar e considerar somente o fim quantificável, a produtividade do trabalho, a noção que Schwartz (2011) traz sobre a criação de normas é interessante. As representaçóes do agir humano, segundo o autor, cada vez mais são dominadas por modelos instituídos que nos autorizam a programar, a organizar e a enquadrar todos os tipos de existência, antecipando a atividade. Por um lado, essas normas nos possibilitam uma vida em sociedade, por outro, há o risco de serem utilizadas de forma a manipular as relações, sendo ferramentas para dominar, explorar e garantir posiçōes de poder. Ou seja, as normas facilitam, mas também são ferramentas de opressão da vida em sociedade.

O risco de nos utilizarmos desses modelos instituídos é o de perdermos a vivacidade de estar vivo, de deixarmos de nos surpreender com a potência criativa da própria vida. $\mathrm{O}$ conceito de atividade que o autor propõe vai justamente destacar a importância do debate de normas, as quais podem nos ajudar a transformar em protocolo aquilo que pode ser protocolado, porém, a antecipação exaustiva é, segundo o autor, impossível, "nenhum protocolo, nenhuma norma antecedente, nenhuma prescrição poderá abstrair o vazio de normas" (Schwartz, 2011, p. 138). 
As normas protocoladas deixam, portanto, lacunas, por não darem conta das múltiplas variáveis nas relações de cada um no trabalho, o que nos obriga a renormatizar as situações e produzir novos "saberes locais" (Schwartz, 2011, p. 138). As autoras Barros e Barros (2007) também se colocam a pensar na potência da formação em situação de trabalho (em equipe). Ou seja, apostam na experiência cotidiana, em ato, e na reflexão da prática como modo de repensar e reconstruir o próprio trabalho, constituindo novos saberes que possam preencher essas lacunas dos protocolos. A questão que se coloca para a discussão do trabalho não é dispensar as prescrições, até porque o prescrito já foi uma vez criação, tendo um importante papel no processo de desnaturalização e de reconstrução de práticas. O ponto para o qual Barros e Barros (2007) nos convidam a atentar é como os trabalhadores, no encontro com a experiência, com o outro, com o inesperado e com o não prescrito, irão avaliar, decidir e intervir em determinadas situações.

\section{A EXPERIÊNCIA NO COTIDIANO DO TRABALHO NA ASSISTÊNCIA}

Durante a experiência de estágio no contexto da assistência social de Porto Alegre, em 2012, mais especificamente em um Centro de Referência Especializado de Assistência Social, foi possível participar do processo de implementação do SUAS na cidade, iniciado há, então, dois anos. Ainda que tenhamos cerca de dez anos desde a publicação da PNAS, são visíveis os impasses que se apresentam no cotidiano do trabalho envolvendo algumas diretrizes e "normas de operacionalização" da política. De fato, acreditamos, conforme já viemos discutindo neste escrito, que uma série de protocolos não é suficiente para determinar as ações e as intervenções em políticas públicas, e que as condições e situações do trabalho cotidiano exigem açôes e atitudes singulares que extrapolam as normativas previamente propostas.

A equipe desse serviço é referência para um território bastante populoso, o que é possível avaliar em comparação com os demais territórios da cidade. Nesse território, os serviços de assistência social, e não só, mas também os de educação e de saúde, acolhem muitas situações envolvendo exploração infantil - sexual e de trabalho -, além do intenso tráfico de drogas, com o qual muitos jovens e crianças estão envolvidos. Durante o estágio, através do acompanhamento desses jovens que chegavam até o serviço em função das medidas socio-educativas em meio aberto, podíamos acompanhar a dinâmica do tráfico e como esses jovens se organizam e se deslocam pelas regiões da cidade. Além disso, as situações de "guerras" entre grupos, entre facções, entre "bondes" (conforme eles mesmos se 
referiam), as mortes frequentes e seus efeitos gerados na comunidade acabavam exigindo que as famílias se deslocassem para outras regiōes, muitas vezes sem que o profissional de referência no serviço e a equipe ficassem sabendo, dificultando acompanhá-las nesse fluxo. Nesse sentido, além dos encaminhamentos entre serviços, entre regióes, nos referimos à necessidade de acompanhar os fluxos de vida, ao invés de prescrever os caminhos, colocando em prática uma política que aposte no trabalho com os territórios existenciais desses sujeitos, antes mesmo do território geográfico.

Muitas vezes, a equipe se deparava com situaçôes extremamente difíceis: os jovens de toda a região chegavam para os acompanhamentos das medidas e, muitos deles pertencendo a grupos "contra", inimigos entre si, ao se "cruzarem" na sala de espera do CREAS, exigiam da equipe novas estratégias para continuar o acompanhamento de todos. $\mathrm{Na}$ Assistência, trabalhamos com a noção de proteção social, sendo o CREAS um dos equipamentos que tem como função a garantia dessa proteção. Situações como a descrita, portanto, colocam a equipe a trabalhar diretamente com a proteção de vidas, quando o risco que se corre é o de mais mortes, ali mesmo, na chegada ou partida de um grupo ou de um atendimento. Essas situações não estão descritas em cartilhas nem previstas nas orientações para o trabalho em um CREAS, são situações em que o trabalhador é convocado a criar, por vezes, rapidamente, com os recursos que existem.

Além das questôes com o tráfico que nos envolviam com intensidade, nos deparávamos com situações familiares bastante complexas. Além da pobreza extrema, as situações de violação de direitos colocavam impasses éticos, tensionando valores entre trabalhadores, entre equipes, entre a rede intersetorial, e principalmente com os usuários.

Nas condições possíveis para sobreviver, muitos sujeitos e famílias se organizavam como podiam e como entendiam que devesse ser. Nas situaçóes que envolviam a "negligência" familiar, muitas vezes nos encontrávamos questionando as açōes realizadas como sendo, elas próprias, violações àqueles usuários que passavam por vários serviços e eram exigidos de muitas maneiras: exigia-se tratamento para abuso de drogas, acompanhamento no CREAS, frequência das crianças na escola e não trabalhando na rua. Situações de crianças trabalhando, muito embora suas famílias estivessem recebendo bolsa-auxílio (pelo Programa de Erradicação do Trabalho Infantil) para que não trabalhassem, configuravam, sob o ângulo de determinadas análises, situação de risco. Porém, percebíamos que tais situações podiam ser um modo de a criança escapar de situações também violentas em casa, marcadas pela negligência, e ser acolhida no ambiente do trabalho. 
São situações que não podem somente ser avaliadas de modo individualizado, nem mesmo individualizante, por tratar-se de uma comunidade inteira que é afetada e se envolve com as questôes de tráfico, de violência, de pobreza, de desamparo político, enfim, situações que, nas suas diferenças, se reproduzem de família em família.

Apesar de reconhecer toda a complexidade dessas situações, o que se configurava na equipe era uma organização burocrática do trabalho. Na tentativa de "incluir" todas as situações que chegavam ao CREAS, essa equipe decidiu distribuir um técnico para cada vila que compunha a região do serviço, para o atendimento especializado em famílias e indivíduos em situação de rua, e outros dois para o atendimento às Medidas Socioeducativas. Um técnico era referência e conduzia o atendimento de um número exorbitante de famílias e sujeitos, ou melhor, tentava conduzir solitariamente situações que exigiam não somente técnica e "especialidade", como pressupõe a política, mas energia emocional e física (porque também nos deslocávamos fisicamente nesses atendimentos), sem a possibilidade de apoio em um trabalho coletivo.

Durante o ano de estágio, e ainda após ele, no contato além do trabalho, foi possível acompanhar o sofrimento e o adoecimento de uma equipe que não recebeu, embora se tenha solicitado tantas vezes, apoio dos gestores da instituição reguladora da assistência no município, tanto no sentido de repensar sobre essas "quantidades", de população a acolher em razão da quantidade de trabalhadores, quanto para que se efetivasse um acompanhamento dos profissionais em equipe, coletivamente. Nessas tentativas que alguns trabalhadores fizeram de apontar e pedir esse apoio, ocorreram transferências e realocamento dos profissionais, escancarando o funcionamento de uma lógica individualista e excludente. Ficava claro que não somente os usuários dessa política estavam imersos em situações vulneráveis, mas também os trabalhadores, que, vendo-se limitados na esfera da criação de meios "coletivos" para agir, acabam por ter sua saúde atingida.

Assim, pensamos que a proposição de espaços de criação de estratégias entre a equipe, espaços em que as experiências singulares possam ser narradas e compartilhadas entre os trabalhadores, agenciando novas práticas, possibilitando novas intervençôes e formas outras de realizar atendimentos e acompanhamentos, poderia ser um caminho potente de alívio desses sofrimentos. Espaços nos quais exista "uma disposição de conviver com o outro aprendendo sobre o que ele faz, como faz, por que faz, conhecendo seus valores e suas possíveis renormatizações" (Barros \& Barros, 2007, p. 80).

O trabalhador, embora no extremo de sua dedicação, também pode, por vezes, se ver em dúvida quanto a suas intervençôes, e é criando um intervalo 
possível de respiro e reflexão que sua saúde e seu trabalho se fortalecem. Afinal, o limiar entre a tutela e a proteção, o direito e a violência, o acompanhamento e o atropelamento, constitui bordas muito sutis, divisas que não se garantem com prescrições, mas que de fato vão se construindo em cada situação. Acreditamos que é justamente pelo debate a respeito do que os trabalhadores fazem para gerir a distância entre o trabalho prescrito e o trabalho real que se evidencia a insuficiência dos "saberes prévios sobre o fazer", expressando produção de saberes engajados no trabalho em situação.

Por nossa experiência, pôde-se indagar, além disso, se os emaranhados de relações pessoalizadas entre os trabalhadores da instituição municipal de assistência estavam dificultando a garantia de ações de cuidado da equipe, uma vez que a prioridade era a manutenção de determinados "elos políticos". Essas situações ainda são frequentes nas políticas públicas do país, sustentando um discurso privatista. E, enquanto isso, uma equipe se decompunha, e exigiase a monitoração quantitativa do trabalho como forma exclusiva de avaliar a "eficiência" e a "funcionalidade" do serviço. Fato esse que remete para o atravessamento capitalístico na esfera do trabalho público.

\section{O TRABALHO EM ATO E A RECONSTRUÇÃO DA PNAS}

Em texto sobre a micropolítica do trabalho vivo em ato, na saúde, Mehry (2009) apresenta o conceito de intercessores. Tal conceito refere-se a um encontro "entre", um processo singular que, sendo um acontecimento produtivo, é disparador de novos processos de subjetivação. Esse encontro entre sujeitos e o espaço intercessor que se produz nas relações, para o autor, é fundamental em uma análise dos processos de trabalho. Isto, por serem:

Lugares de construção de processos e produtos que existem para os "dois" em ato, não tendo existência sem este momento em fluxo, no qual os "inter" se colocam como "entreinstituintes" em busca de um processo de instituição, muito próprio de um sujeito coletivo novo que se forma ali em ato no encontro (Mehry, 2009, p. 286).

Podemos aproximar o que o autor propóe pensar, no campo da saúde pública, dos processos de trabalho no campo da assistência social. Na sua visão, a mudança efetiva dos processos de trabalho só é possível ao serem incorporadas novas questões pela micropolítica do trabalho, ou seja, não só pelos questionamentos sobre o modelo de organização instituído na estrutura dos serviços, mas também pelo olhar para o trabalho vivo em ato, que também produz as configurações instituídas. Mehry (2009) afirma que "as relaçôes macro e micropolíticas na saúde encontram-se nos espaços de gestão do processo de trabalho e das 
organizações em saúde" (p. 299). Assim, coloca-se em questão a capacidade e a autonomia que todo trabalhador tem de "autogovernar" o seu trabalho, sendo ele próprio trabalho vivo em ato, reposicionando a concepção de gestão não mais do trabalho, mas no trabalho.

Por um lado, portanto, compreendemos que as mudanças estruturais da organização da assistência social que acompanharam e ganharam força com as lutas pela saúde pública por movimentos sociais, a partir da PNAS e da implementação do SUAS, já produziram perturbações nos modos naturalizados de trabalhar na assistência. As novas concepçóes, tanto sobre os sujeitos que acessam esses serviços quanto sobre a função da própria política que se reposiciona frente ao usuário cidadão, possuidor de direitos e potências, por si só desarranjam modos já estabelecidos de um fazer "assistência social privatista". Por outro lado, é necessário considerar que tais mudanças, apesar de só terem sido possíveis a partir da discussão ampliada nas instâncias participativas da assistência, necessitam de permanente investimento. Principalmente, como viemos discutindo, na esfera micropolítica do trabalho, de modo a potencializar a produção desses encontros "entre", dando visibilidade e atenção para esses momentos de encontro no cotidiano que, no furor do trabalho ditado pela urgência das situações, não ganham espaço para reflexão.

Ferigato e Carvalho (2009) apontam para a existência de diferentes linhas de poder no modelo de atenção em saúde, havendo uma composição de modelo de atenção que se dá por aspectos estruturais, determinantes macropolíticos e macroeconômicos, tramados pelas linhas de força que se atualizam e são reproduzidas na prática cotidiana, na instituição, por cada sujeito. Ao compreendermos que a gestão do trabalho e da própria política, na assistência, se dá de forma transversal, com comunicação lateralizada entre os diferentes setores e especialidades, e não somente verticalizada, é possível enlaçar as demandas coletivas àquilo que se propõe enquanto política de fato pública, e não submetida aos interesses privados, e até mesmo privatizantes do próprio Estado.

Para tanto, é necessário reformular tanto os "valores políticos", segundo os mesmos autores, quanto o sistema de conceitos teóricos que orientam o trabalho na saúde, e aqui, no que compete à nossa discussão, o trabalho na assistência. Ou seja, nessa composição subjetiva e objetiva da gestão do trabalho, Ferigato e Carvalho (2009) apontam para alguns caminhos possíveis para a construção de novas formas de pensar a gestão em saúde, que trazemos para a gestão na assistência social. Dentre eles, o fortalecimento dos sujeitos envolvidos nesse contexto, e que exige de esses atores a capacidade analítica das situações, sendo preciso entender que cada ação de gestão "é um ato eminentemente ético- 
político que reflete sobre os usos que fazemos do nosso saber-poder sobre pessoas e comunidades, ou com pessoas e comunidades" (Ferigato \& Carvalho, 2009, p. 69).

No mesmo fluxo de pensamentos, Barros, Guedes e Roza (2011) afirmam que o desafio no trabalho é "fomentar nessa rede o exercício do protagonismo dos sujeitos e convocar o potencial criativo próprio da vida para a construção de novos modos de gerir o trabalho que não sejam novas formas de assujeitamento" (p. 4803). Para as autoras, o risco de se ter uma organização do trabalho que se fundamenta em uma gerência que ignora a autonomia do trabalhador em gerir o seu fazer - que não afirma os processos de cogestão no trabalho - é que, assim, tende-se a produzir "subjetividades amorfas" (Barros, Guedes, \& Roza, 2011, p. 4805), que são moldadas e moldáveis ao saber dos interesses do capital, impedindo processos de resistência às instituições e às técnicas de controle, subjetividades engolidas pela disciplinarização.

Conforme a leitura que Barros e Barros (2007) fazem de Deleuze, é somente no plano dos encontros engendrados do cotidiano, lançados ao campo dos afetos, daquilo que nos toca e sensibiliza a alma, que se fará suscitar o problema. Se aproximarmos o que os autores anteriormente citados afirmam, é na prática cotidiana, nesse campo dos afetos, que percebemos as normas e os protocolos se esgotando, no seu alcance em prever e enquadrar o agir de cada um. Até este momento da discussão, firmamos a aposta nos arranjos coletivos, na capacidade de autoavaliação e autogestão dos atores da assistência, e na análise micropolítica dos processos de trabalho, como forma de resistência às políticas de governo da vida, que aprisionam os corpos e as mentes impondo padrões racionais e formas de controle de tudo e todos que extravasam em afeto.

É necessário apostar na formação de equipes que operem como coletivos, deixando de considerar a instituição, conforme Saidón (2008a) coloca, "como um receptáculo vazio das forças sociais, para poder observar a si mesma em sua permanente atividade, produtora constante de novos agenciamentos que transformam efetivamente relações e práticas no espaço social” (p. 131). Saidón retoma o conceito de devir no trabalho em instituições: "Habitar um devir é instalar-se em uma zona de co-presença; é trabalhar em um encontro; é evocar o estranho em nós com os outros; é a troca que acontece a uma partícula ao entrar em uma zona de indeterminabilidade e de potenciais processos criativos" (Saidón, 2008b, p. 95).

Além disso, o autor aponta que a criação de novas formas de ser e de existir só é possível quando existe a disponibilidade aos encontros, aos afetos e à "transmutação radical de valores que inaugura um pensamento e que se traduz 
na criação de territórios existenciais inéditos" (Saidón, 2008b, p. 91). É a própria política de assistência social se reconstruindo, permanentemente. Compartilhar as vicissitudes da atividade no trabalho, no coletivo, é habitar uma postura ética, não utilizando normas vigentes para exercer um poder de modo opressivo nas relações cotidianas, mas apostando nas relaçôes verticalizadas que ajudam o coletivo a resistir às formas de dominação que nos destituem da possibilidade de nos afetar e de criar alternativas de vida.

Nesse sentido, retomamos o escrito de Deleuze (2002) sobre o conceito de Ética, desenvolvido por Espinosa, no qual se propóe a ideia de que, "quando um corpo encontra outro corpo, uma ideia, outra ideia, tanto acontece que as duas relações se compóem para formar um todo mais potente, quanto que um decompõe o outro e destrói a coesão das suas partes” (p. 25). Tal passagem possibilita pensar as novidades que o trabalho com a assistência enquanto política pública nos propõe, que não se trata de excluir fundamentos ou concepções iniciais, mas permitir que nos encontros com outros corpos - com outros campos de atuação, com outros saberes até então estranhos aos nossos - a relação dessas noções possa formar novos compostos. Se a própria equipe responsável por garantir o acompanhamento dos usuários da assistência estiver vulnerável, enquanto coletivo, aos modos de dominação nas relações de trabalho, corre-se o risco de, no encontro com o usuário, essas relações e esse contexto de violações serem reproduzidos.

\section{DAS CONSIDERAÇÕES FINAIS ÀS DISCUSSÕES PERMANENTES}

A intenção de discutir os processos de trabalho no contexto da assistência social, neste escrito, vem de encontro às publicaçôes e debates acerca da gestão e das relaçooes de trabalho na saúde pública, no país.

Embora já haja efeitos evidentes de como a reorganização do próprio SUS, a criação de novos projetos e a atenção para as equipes que compõem os serviços (temos a Política Nacional de Humanização que aponta também para o cuidado com os trabalhadores da saúde), esse discurso que afirma o entrelaçamento potente entre sujeitos e que articula "modelos de atenção e modelos de gestão em direção à transversalidade do poder entre os atores que compõem a rede" (Ferigato \& Carvalho, 2009, p. 70) ainda toca uma parcela pequena do conjunto de usuários, trabalhadores e gestores, segundo os autores. As reflexôes sobre os modos instituídos no trabalho, efeito desse discurso, continuam fazendo resistência aos modos endurecidos de se pensar a gestão apenas como função de um cargo, e não de um saber-poder sobre saúde que todos os envolvidos com 
ela possuem e podem compartilhar, mas precisam ser ampliados para o debate ganhar força.

Tendo em vista que a PNAS fora aprovada no ano em que a Política Nacional de Humanização em Saúde também ganhara forma definida, e que a ela se constitui em meio a movimentos sociais que repensam as intervençôes e açôes públicas, ou ainda a própria função de Estado, é possível utilizar as produções no campo da saúde para refletir sobre os modelos instituídos também na assistência. Mais do que isso, utilizamos os estudos e debates dessas ferramentas que se construíram no campo da saúde para fazer a análise dos processos de trabalho, no interior das equipes dos serviços de assistência social. Apostamos nesses novos modos de gestão no trabalho como instrumento de produção de subjetividades autônomas e ativas, ou seja, no fortalecimento de sujeitos com capacidade de análise e intervenção no cotidiano do trabalho (Ferigato \& Carvalho, 2009).

Ressaltar a dimensão subjetiva nos processos de trabalho na assistência enquanto ferramenta de gestão do/no trabalho, ainda no diálogo com Ferigato e Carvalho (2009), é incluir a relação do sujeito consigo, relação que resiste aos códigos e poderes e, portanto, "escancara a nossa capacidade de agir sobre as nossas próprias ações" (p. 67). Assim, quando se aposta na autonomia dos sujeitos, usuários e trabalhadores, para práticas de governo, considerando-se que nas malhas do poder os sujeitos circulam e estão sempre em posição de exercer o poder e sofrer sua ação, nunca sendo alvo inerente, reconhece-se todo sujeito como uma pessoa que age e valoriza-se sua capacidade de resistir às hegemonias e de interferir nas malhas da dominação.

Feita essa observação sobre o potencial de revolta que constitui todo agir humano, acreditamos que é compromisso ético do trabalhador manter-se disponível e implicado com os encontros do cotidiano, tornando-se afeito à desterritorialização dos saberes e das formas dominantes e opressoras nas relações do trabalho da assistência, afirmando a potência dos coletivos na criação de estratégias que garantam uma política da diversidade, uma política pública de fato. 


\section{REFERÊNCIAS}

Aguinsky, B. G., Fernandes, I., \& Tejadas, S. S. (2009). Entre a garantia de direitos e o reforço à subalternização: concepções e práticas ainda em disputa sobre o público-alvo da Política de Assistência Social. In J. M. R., Mendes, J. C., Prates, \& B. G., Aguinsky (Orgs.). O Sistema Único de Assistência Social: entre a fundamentação e o desafio da implementação. (pp. 63-82). Porto Alegre; Edipucrs.

Barros, M. E. B. de, \& Barros, R. B. (2007). A Potência Formativa do Trabalho em Equipe no Campo da Saúde. In R., Pinheiro, M. E. B. de, Barros, \& R. A. de, Mattos, (Orgs.). Trabalho em equipe sob o eixo da integralidade: valores, saberes e práticas. (pp. 75-84). Rio de Janeiro: IMS/UERJ: CEPESC: ABRASCO.

Barros, M. E. B., Guedes, C. R., \& Roza, M. M. R. (2011). O apoio institucional como método de análise-intervenção no âmbito das políticas públicas de saúde: a experiência em um hospital geral. Ciência \& Saúde Coletiva, 16(12), 48034814.

Barros, M. E. B.; Pimentel, E. H. C. (2012). Políticas públicas e a construção do comum: interrogando práticas PSI. Polis e Psique, 2(2), 3-22.

Brasil. Ministério do Desenvolvimento Social e Combate à Fome: Secretaria Nacional de Assistência Social (1993). Loas Anotada: Lei Orgânica da Assistência Social. Recuperado a partir de http://www.mds.gov.br/webarquivos/ publicacao/assistencia_social/Normativas/LoasAnotada.pdf

Brasil. (2004, Setembro). Política Nacional de Assistência Social. Brasília: MDS. Recuperado a partir de http://lproweb.procempa.com.br/pmpa/prefpoa/fasc/ usu_doc/pnas.pdf.

Couto, B. R. (2009). O Sistema Único da Assistência Social - SUAS: na consolidação da Assistência Social enquanto política pública. In L. R. da, Cruz, \& N., Guareschi, (Orgs.). Politicas públicas e assistência social: diálogos com as práticas psicológicas. (pp. 41-55). Petrópolis; Editora Vozes.

Couto, B. R., \& Silva, M. B. (2009). A política de assistência social e o Sistema Único de Assistência Social: a trajetória da constituição da política pública. In J. M. R., Mendes, J. C., Prates, \& B. G., Aguinsky, (Orgs.). O Sistema Único de Assistência Social: entre a fundamentação e o desafio da implementação. (pp. 31-43). Porto Alegre: EDIPUCRS. 
Cruz, L. R. da, \& Guareschi, N. M. de F. (2009). A constituição da assistência social como política pública: interrogações à psicologia. In L. R. da, Cruz, \& N. M. de F. Guareschi (Orgs.). Políticas públicas e assistência social: diálogos com as práticas psicológicas. (pp. 13-40). Petrópolis: Editora Vozes.

Deleuze, G. (2002). Espinosa: filosofia prática. São Paulo: Escuta.

Ferigato, S., \& Carvalho, S. R. (2009). O poder da gestão e a gestão do poder. In S. R., Carvalho, M. E., Barros, \& S., Ferigato, (Orgs.). Conexões: Saúde Coletiva e Políticas de Subjetividade. (pp. 53-73). São Paulo; Editora Hucitec.

Lazzarotto, G. D. R., \& Carvalho, J. D. (2012). Afetar. In T. M. G., Fonseca, M. L., Nascimento, \& C., Maraschin, (Orgs.). Pesquisar na diferença: um abecedário. (pp. 25-27). Porto Alegre; Editora Sulina.

Mehry, E. E. (2009). Enfrentar a lógica do processo de trabalho em saúde: um ensaio sobre a micropolítica do trabalho vivo em ato, no cuidado. In S. R., Carvalho, M. E., Barros, \& S., Ferigato, (Orgs.). Conexōes: saúde coletiva e politicas de subjetividade. (pp. 276-300). São Paulo: Hucitec.

Mestriner, M. L. (2008). O Estado entre a filantropia e a assistência social. (3a ed.). São Paulo; Cortez Editora.

Rocha, M. L., Montano, S. F., \& Pimenta, T. J. (2012). Pesquisas participativas e a pesquisa-intervenção na escola. In A. M., Jacó-Vilela, A. C., Cerezzo, \& H. B. C., Rodrigues (Orgs.). Clio-Psyché Hoje: Fazeres e dizeres psi na história do Brasil. (pp. 290-301). Rio de Janeiro; Centro Edelstein de Pesquisas Sociais.

Saidón, O. (2008a). Rumo a uma clínica institucional. In O., Saidón. Devires da clínica. (pp. 121-137). São Paulo: Hucitec.

Saidón, O. (2008b). A ciência do devir: devir mulher, devires minoritários. In O., Saidón. Devires da Clínica. (pp. 91-98). São Paulo: Hucitec.

Schwartz, Y. (2011). Manifesto por um ergoengajamento. In P. F., Bendassolli, \& L. A. P. Soboll (Orgs.). Clínicas do trabalho. (pp. 132-166). São Paulo, Editora Atlas. 